\title{
Should Children With Acute Asthma Exacerbation Receive Inhaled Anticholinergics?
}

\author{
Dylan D. Cooper and Julie L. Welch
}

Department of Emergency Medicine, Indiana University School of Medicine, Indianapolis, IN

\section{Take-Home Message}

The use of inhaled anticholinergics (ipratropium bromide) along with inhaled short-acting $\beta$-agonists (albuterol) can reduce hospital admission rates in children with moderate to severe asthma exacerbations.

\section{Methods}

\section{Data Sources}

In this updated review, the authors added to an initial search of MEDLINE (1966 to April 2000), EMBASE (1980 to April 2000) and CINAHL (1982 to April 2000), by including "all years" of the Cochrane Airways Group Register of Trials (searched April 18, 2012). In addition, they searched the reference lists of relevant reviews and contacted both the manufacturer of ipratropium bromide and researchers in the field of pediatric asthma.

\section{Study Selection}

All randomized control trials comparing anticholinergic plus short-acting $\beta$-agonists with short-acting $\beta$ agonists alone in pediatric patients with acute asthma exacerbation (aged 18 months to 18 years) were reviewed. The primary outcome was hospital admission; secondary outcomes measured at 60 and 120 minutes after the last combined anticholinergic and short-acting $\beta$-agonist dose included change from baseline in percentage of predicted forced expiratory volume, change in percentage from baseline in

This is the author's manuscript of the article published in final edited form as: 
forced expiratory volume, change from baseline in respiratory resistance, change from baseline in clinical score, oxygen saturation, need for repeated inhaled treatments, need for systemic corticosteroids, adverse events, and relapse rate.

\section{Data Extraction and Synthesis}

Two authors independently extracted data and assessed study trial quality (using the Grading of Recommendations Assessment, Development and Evaluation rating system for primary outcome). Disagreements were resolved by consensus. Risk of bias was assessed by 1 author and 1 member of the Cochrane Airways Group as high, low, or unclear. Treatment effects were assessed in pooled risk ratios (RRs) for dichotomous outcomes and mean difference for continuous outcomes. The Cochrane statistical package, RevMan version 5.1 (The Nordic Cochrane Center, Copenhagen, Denmark), was used to calculate pooled RRs, using the fixed-effect model or the random-effects model if there was substantial, unexplained heterogeneity. A subgroup analysis was conducted on the intensity of anticholinergic administration, cointervention with glucocorticoids, and severity of the asthma exacerbation.

\section{Results}

Twenty trials met inclusion criteria for analysis. Fifteen studies published hospital admissions, were found to be high quality with low risk of bias, and were used for data analysis. (Table).

\section{Commentary}

Acute asthma exacerbations account for more than 1.8 million emergency department visits per year, with a higher prevalence in children (9.5\%) than adults $(7.7 \%) .{ }^{1}$ The standard practice of care for pediatric asthma involves the administration of inhaled short-acting $\beta$-agonists, which directly relax smooth muscles, and systemic steroids, which reduce airway inflammation. Inhaled anticholinergics

This is the author's manuscript of the article published in final edited form as:

Cooper DD, Welch JL. Ann Emerg Med. 2015 Jan;65(1):83-4.

http://dx.doi.org/10.1016/i.annemergmed.2014.06.014 
decrease airway resistance by reducing both bronchoconstriction and mucus secretion. ${ }^{2}$ This systematic review demonstrates that inhaled anticholinergics (specifically, ipratropium bromide), along with shortacting $\beta$-agonists (specifically, albuterol) reduce the number of hospital admissions for pediatric patients with acute moderate to severe asthma exacerbations. However, using the combined inhaled treatments does not seem to reduce the risk of a recurrent asthma attack.

In subgroup analysis, both the multiple-dose anticholinergic and more severe asthma exacerbation subgroups showed a significant reduction in hospital admissions, whereas single-dose and lowerseverity subgroups showed no statistically significant effect. The most beneficial dose, intensity, and duration of inhaled treatments could not be concluded. Adverse events in the anticholinergic plus shortacting $\beta$-agonist treatment groups included less tremor and nausea, with no difference in vomiting, compared with adverse events with short-acting $\beta$-agonists alone. Recent small studies have examined the use of long-acting anticholinergics in the management of adult asthmatic patients with poorly controlled disease, yet pediatric studies have not been reported. ${ }^{3}$ The reduction in hospital admissions, improvement in adverse events, ease of administration with short-acting $\beta$-agonists, and availability support the regular use of multiple-dose, inhaled anticholinergics with short-acting $\beta$-agonists in the treatment of acute pediatric asthma exacerbations.

This is the author's manuscript of the article published in final edited form as: 


\section{References}

1. J.E. Moorman, L.J. Akinbami, C.M. Bailey, et al. National Surveillance of Asthma: United States, 2001-2010. National Center for Health Statistics. Vital Health Stat 3 (2012), pp. 1-67.

2. F.R. Coulson, A.D. Fryer. Muscarinic acetylcholine receptors and airway diseases. Pharmacol Ther, 98 (2003), pp. 59-69.

3. H.A. Kerstjens, M. Engel, R. Dahl, et al. Tiotropium in asthma poorly controlled with standard combination therapy. N Engl J Med, 367 (2012), pp. 1198-1207.

Editor's Note: This is a clinical synopsis, a regular feature of the Annals' Systematic Review Snapshots (SRS) series. The source for this systematic review snapshot is: Griffiths B, Ducharme FM. Combined inhaled anticholinergics and short-acting beta2-agonists for initial treatment of acute asthma in children. Cochrane Database Syst Rev. 2013;8:CD000060. http://dx.doi.org/10.1002/14651858.CD000060.pub2. 


\begin{tabular}{|c|c|c|c|c|c|}
\hline $\begin{array}{l}\text { Primary } \\
\text { Outcome }\end{array}$ & $\begin{array}{l}\text { Control Risk: } \\
\text { SABA Alone }\end{array}$ & $\begin{array}{l}\text { Anticholinergic and } \\
\text { SABA Risk }(95 \% \mathrm{Cl})\end{array}$ & $\begin{array}{l}\text { Relative } \\
\text { Effect<comma> RR } \\
(95 \% \mathrm{Cl})\end{array}$ & $\begin{array}{l}\text { Number Needed to } \\
\text { Treat<comma> NNT }(95 \% \mathrm{Cl})\end{array}$ & $\begin{array}{l}\text { Heterogeneity }(12 \\
\text { Index) }\end{array}$ \\
\hline $\begin{array}{l}\text { Hospital } \\
\text { admission }\end{array}$ & $23 / 100$ & $17 / 100(15-20)$ & $0.73(0.63-0.85)$ & $16(12-29)^{*}$ & 0 \\
\hline
\end{tabular}

This is the author's manuscript of the article published in final edited form as:

Cooper DD, Welch JL. Ann Emerg Med. 2015 Jan;65(1):83-4. http://dx.doi.org/10.1016/i.annemergmed.2014.06.014 